\title{
Direitos humanos e princípios comuns entre inteligência artificial e direito à saúde
}

Human rights and common principles between artificial intelligence and the right to health

Derechos humanos y principios comunes entre la inteligencia artificial y el derecho a la salud

Maria Eliane Alves de Sousa ${ }^{1}$

\section{Resumo}

Objetivo: encontrar possíveis convergências e desdobramentos entre os princípios do direito à saúde, da Declaração Universal sobre Bioética e Direitos Humanos e da Recomendação do Conselho sobre Inteligência Artificial da Organização para a Cooperação e o Desenvolvimento Econômico. Metodologia: pesquisa bibliográfica em textos acadêmicos sobre a principiologia em direito à saúde e pesquisa documental em instrumentos jurídicos internacionais do soft law - Declaração Universal sobre Bioética e Direitos Humanos e a Recomendação sobre Inteligência Artificial do Conselho da Organização para a Cooperação e o Desenvolvimento Econômico. Resultados: os princípios convergem para eixos que permitem dividi-los em três grandes categorias: mais tradicionais (biológicas, biotecnológicas e biomédicas); amplas e inclusivas (sanitária, social, cultural, econômica, laboral, ambiental, moral e ética); e organizativas-jurídicas (responsabilidade individual, social, coletiva e política). Conclusão: os princípios devem embasar e equilibrar as políticas sociais em interligação ativa com o sistema de proteção jurídico-social de uma sociedade democrática. A convergência entre os princípios centra-se na dignidade humana, guiando para que as decisões tomadas sobre os sistemas de inteligência artificial em saúde e sua implementação sejam feitas de forma segura, imparcial e justa para toda a sociedade.

Palavras-chave: Inteligência artificial. Tecnologias em saúde. Bioética. Políticas públicas. Dignidade humana e justiça social.

\begin{abstract}
Objective: to find possible convergences and developments between the principles of the right to health, the Universal Declaration on Bioethics and Human Rights and the Recommendation of the Council on Artificial Intelligence of the Organization for Economic Cooperation and Development. Methods: bibliographic research in academic texts on the principle of right to health and documentary research in legal instruments of soft law: the Universal Declaration on Bioethics and Human Rights and the Council Recommendation on Artificial Intelligence of the Organization for Economic Cooperation and Development. Results: the principles converge to axes that allow dividing them into three major categories: more traditional (biological, biotechnological and biomedical); broad and inclusive (health, social, cultural, economic, labor, environmental, moral and ethical); and organizational-legal (individual, social, collective and political responsibility). Conclusion: the principles must underpin and balance social policies in active interconnection with the legal and social protection system of a democratic society. The convergence between the principles focuses

${ }^{1}$ Doutoranda em Direito, Universidade Federal da Bahia, Salvador, Bahia, Brasil; professora, Universidade Estadual da Bahia, Ilhéus, Bahia, Brasil. https://orcid.org/0000-0003-0365-9989. E-mail: measud7@gmail.com
\end{abstract}


on human dignity, guiding so that decisions made about artificial intelligence systems in health and their implementation are made in a safe, impartial and fair manner for the whole of society.

Keywords: Artificial intelligence. Health technologies. Bioethics. Public policy. Human dignity and social justice.

\section{Resumen}

Objetivo: encontrar posibles convergencias y desarrollos entre los principios del derecho a la salud, la Declaración Universal sobre Bioética y Derechos Humanos y la Recomendación del Consejo sobre Inteligencia Artificial de la Organización para la Cooperación y el Desarrollo Económicos. Metodología: investigación bibliográfica en textos académicos sobre el principio del derecho a la salud e investigación documental en instrumentos jurídicos de soft law: la Declaración Universal sobre Bioética y Derechos Humanos y la Recomendación del Consejo sobre Inteligencia Artificial de la Organización para la Cooperación y el Desarrollo Económicos. Resultados: los principios convergen en ejes que permiten dividirlos en tres grandes categorías: más tradicionales (biológicos, biotecnológicos y biomédicos); amplio e inclusivo (sanitario, social, cultural, económico, laboral, medioambiental, moral y ético); y organizacional-legal (responsabilidad individual, social, colectiva y política). Conclusión: los principios deben apuntalar y equilibrar las políticas sociales en interconexión activa con el sistema legal y de protección social de una sociedad democrática. La convergencia entre los principios se centra en la dignidad humana, orientando para que las decisiones que se tomen sobre los sistemas de inteligencia artificial en salud y su implementación se tomen de manera segura, imparcial y justa para toda la sociedad.

Palabras clave: Inteligencia artificial. Tecnologías sanitarias. Bioética. Políticas públicas. Dignidad humana y justicia social.

\section{Introdução}

Os desafios que o mundo cibernético impõe ao campo do Direito transitam em torno de temas como privacidade digital e segurança digital, mas também inclusão e acesso às novas tecnologias. Requerem um arcabouço que responda às fortes mudanças de concepção, padrões, direitos e deveres da sociedade, inclusive com exigências e consequências não previstas no âmbito jurídico das liberdades.

Apesar de surgidos novos campos e estudos no Direito para fazer frente e dar respostas a tais necessidades, a Declaração Universal dos Direitos Humanos (1) é a base de orientação diante dessa evolução, tendo em vista que a dignidade da pessoa humana é o fundamento para liberdade, igualdade, justiça e paz. Existem fatores relacionados às oportunidades de acesso, ao respeito e aos direitos, como o direito à saúde, que podem gerar desigualdades vinculadas e não vinculadas às tecnologias digitais e medicina do futuro, novos fatores que podem delinear iniquidades em saúde (2). 
O progresso tecnológico, em especial por meio da inteligência artificial (IA), traz benefícios para a área da saúde, mas ao mesmo tempo traz mudanças preocupantes, com a possibilidade de suas tecnologias serem absorvidas por pequenos grupos dominantes, embora se proclame que a IA "permite que o cuidado chegue a mais pessoas em áreas vulneráveis, contribuindo, assim, para alcançarmos a saúde universal” (2).

Atualmente, sem maiores preocupações com os impactos bioéticos, a IA está sendo utilizada nos esforços de combate à pandemia do Covid-19. As aplicações acontecem com a utilização de médicos e enfermeiros virtuais para atender dúvidas e orientar a população; com a utilização de algoritmos que podem ajudar a entender o avanço do coronavírus, detectar casos e prioridades de atendimentos em hospitais e direcionar recursos; e na análise de imagens de tomografias realizadas em pulmões para tentar diagnosticar a doença.

O tema é importante porque estimula a compreensão dos direitos humanos como norteadores de compromissos e políticas sociais que favoreçam o desenvolvimento humano, aliado à capacidade tecnológica da medicina do futuro, compatibilizando o uso da IA em saúde segundo preceitos essenciais da bioética.

Este artigo tem como objeto a reflexão sobre os princípios da IA e sua relação com os princípios da bioética no âmbito do direito humano à saúde, a fim de encontrar possíveis convergências entre os princípios, bem como seus desdobramentos.

\section{Metodologia}

Para o alcance dos objetivos, foram comentados dois documentos do soft law: a Recomendação sobre Inteligência Artificial do Conselho da Organização para a Cooperação e o Desenvolvimento Econômico (RIACOCDE) (3) e a Declaração Universal sobre Bioética e Direitos Humanos (DUBDH) (4); bem como textos acadêmicos sobre os princípios do direito à saúde.

A pesquisa, de natureza teórica, foi realizada mediante estudo bibliográfico por revisão narrativa simples de textos teóricos relacionados ao tema, e também estudo documental por levantamento de normativas da RIACOCDE (3) e da DUBDH (4). Todos esses documentos são de domínio público e acesso livre.

Adotou-se, como princípios do direito à saúde (dignidade da pessoa humana, liberdade, igualdade, equidade, consentimento ou autonomia, segurança sanitária, 
informação, participação da comunidade, prevenção, risco, benefício, subsidiariedade, legalidade, supremacia do interesse público, impessoalidade, publicidade, eficiência e moralidade), além dos que estão consagrados na Constituição Federal de 1988 sobre os direitos fundamentais (5). Também foram utilizados os princípios que constam no livro de Jean-Marie Clement (2005), na tese de Fernando Mussa Abujamra Aith (2006) e no artigo de Alexandre Nemer Elias (2008) (6-8). Estes textos foram selecionados por serem os que definem e analisam os princípios do direito à saúde de forma mais detalhada.

Apesar de alguns doutrinadores defenderem haver uma distinção entre direito à saúde e direito sanitário, os princípios foram tomados dentro do amplo entendimento do direito à saúde, conforme art. 196 da Constituição Federal:

direito de todos e dever do Estado, garantido mediante políticas sociais e econômicas que visem à redução do risco de doença e de outros agravos e ao acesso universal e igualitário às ações e serviços para sua promoção, proteção e recuperação (5).

Para a elaboração dos resultados da pesquisa, os princípios foram sistematizados em quadros, apresentando suas convergências e desdobramentos. A partir dos princípios, tais como se apresentavam nos documentos, foram feitos agrupamentos por termos sinônimos, associados ou correlatos. Para tanto, utilizou-se o léxico de bioética de Antonio Pardo (9); o Dicionário Latino Americano de Bioética, publicado pela UNESCO (10); e o site Descritores em Ciências da Saúde (DeCS), da na Biblioteca Virtual em Saúde (11).

\section{Medicina do futuro e uso da inteligência artificial}

A medicina do futuro já está presente na sociedade, tendo como principal aspecto de sua conformação a característica interdisciplinar e multidisciplinar entre pesquisas, práticas e produtos em áreas como bioinformática, biologia de sistemas, inteligência artificial (IA), bioengenharia e ciências de dados.

Desde o século XX a medicina do futuro, por meio de novos conhecimentos científicos e da cibernética, permite diagnósticos cada vez mais precisos e tratamentos personalizados, além de prometer revolucionar a medicina do século XXI. De forma cada vez mais rápida, define a perspectiva e o alcance dos cuidados em saúde para ampliar as possibilidades de cura e aumentar a expectativa e qualidade de vida das pessoas (12).

A IA foi criada na década de 1950 com propósitos de imitar a criatividade, o autoaperfeiçoamento, as estratégias de decisão e o uso da linguagem humana, a partir dos 
estudos pioneiros de Alan Turing (12). No âmbito da saúde, a inteligência artificial é considerada a disrupção digital do processo saúde-doença-cuidado (13). Dois importantes eventos sobre IA e saúde foram realizados em janeiro de 2020 no Brasil: o Hackmed Conference $^{2}$, no Hospital das Clínicas em São Paulo; e o workshop ${ }^{3}$ conjunto entre a Organização Pan-Americana da Saúde (OPAS), a Organização Mundial da Saúde (OMS) e a União Internacional de Telecomunicações (UIT). Em ambos, discutiu-se que a IA permite o acesso a grandes conjuntos de dados (big data) nos serviços de saúde, com informações potencialmente vitais para processar diagnósticos precisos; procedimentos de terapia intensiva; e procedimentos médicos remotos (14)(2).

Todavia, incorporar novos conhecimentos às áreas de prevenção, diagnóstico, tratamento e reabilitação traz impactos nem sempre mensuráveis no momento de sua aplicação (12). As polêmicas sobre a inteligência artificial apareceram a partir de sua idealização por Turing, suscitadas por preocupações sobre o uso de máquinas criadas para imitar o cérebro humano (13).

\section{A Recomendação do Conselho da OCDE sobre Inteligência Artificial}

A Organização para a Cooperação e o Desenvolvimento Econômico (OCDE) é uma organização internacional formada por 35 países membros e 8 países parceiros estratégicos. Foi criada em 1948 após a Segunda Guerra Mundial, para promover o desenvolvimento econômico e o bem-estar social, em apoio aos princípios da democracia representativa. Discute políticas públicas e econômicas que orientem os países a criarem gestão em diversas áreas da atuação governamental, bem como a solução de possíveis problemas de questões econômicas, financeiras, comerciais, sociais e ambientais (15).

Os instrumentos jurídicos elaborados pela OCDE pertencem ao soft law no âmbito do direito internacional, e são normas exaradas pelas organizações internacionais e suas agências. Possuem caráter flexível e de governança, e seus efeitos estão nas relações multilaterais do direito internacional público e privado. A força normativa é limitada, por não serem vinculantes, mas desempenham um papel interpretativo importante na construção e interpretação dos princípios e normas do direito internacional (16). Por ser instrumento jurídico desenvolvido no âmbito da OCDE, uma recomendação não é juridicamente

\footnotetext{
2 http://www.hackmed.com.br/conference-health-hackathon-2020

${ }^{3}$ https://www.paho.org/bra/index.php?option=com_content\&view=article\&id=6097:oms-opas-e-uit-discutem-uso-deinteligencia-artificial-na-saude-durante-workshop-no-brasil\&Itemid=812
} 
vinculativa, mas possui uma grande força moral como representação da vontade política dos países adeptos. Há uma expectativa de que façam o máximo possível para implementá-la (17).

Como uma tentativa de melhor administrar as soluções para os problemas em torno das polêmicas e dos receios quanto ao uso e avanços da IA, em 2019, o Conselho da OCDE aprovou a Recomendação sobre Inteligência Artificial, de 21/05/2019 (3), proposta por sua Comissão de Política da Economia Digital. É o primeiro conjunto de políticas orientadoras sobre IA, que tem como objetivo assegurar que tais sistemas sejam criados e desenvolvidos de forma robusta, segura, justa e confiável. Contém princípios norteadores que visam garantir que a IA seja concebida de modo a considerar o ser humano e seu bem-estar em primeiro lugar, e coloca desenvolvedores e operadores como os responsáveis jurídicos pela sua utilização. A Recomendação teve a adesão dos países membros da OCDE e dos países parceiros, entre estes o Brasil (3).

RIACOCDE é a primeira norma intergovernamental para promover a inovação e a confiança na IA garantindo o respeito pelos direitos humanos e pelos valores democráticos. Foi idealizada para estar em consonância com os Objetivos de Desenvolvimento Sustentável (ODS), estabelecidos na Agenda para o Desenvolvimento Sustentável de 2030 e adotada pela Assembleia Geral das Nações Unidas (A/RES/70/1), para potencializar a transição digital nos países (3). Dentre as recomendações, destaca-se que os governos devem considerar o investimento público de longo prazo e incentivar o investimento privado em pesquisa e desenvolvimento interdisciplinares, a fim de estimular a inovação em uma IA confiável quanto às questões técnicas desafiadoras, implicações sociais, legais, éticas e políticas (3).

Embora não trate de especificidades sobre IA e a área da saúde, a Recomendação traz explicações que justificam a aplicação no uso da IA em geral:

A Inteligência Artificial (IA) é uma tecnologia de uso geral que tem o potencial de melhorar a vida e o bem-estar das pessoas, contribuir para uma atividade econômica global sustentável e positiva, aumentar a inovação e a produtividade e ajudar a responder aos principais desafios globais. Ela é implantada em muitos setores, desde produção, finanças e transporte até saúde e segurança.

Além dos benefícios, a IA também levanta desafios para nossas sociedades e economias, principalmente em relação às mudanças e desigualdades econômicas, competição, transições no mercado de trabalho e implicações para a democracia e os direitos humanos (3). 
Os desafios mais importantes da IA estão nos impactos que pode ocasionar tanto em termos de pesquisas para o seu desenvolvimento, quanto das implicações sociais, políticas, econômicas e éticas de seu uso. Nesse sentido, para o direito à saúde, relacionam-se principalmente aos riscos de danos à vida e interferência nas liberdades individuais, questões do campo da bioética.

\section{Bioética e biodireito: implicações para o uso da IA em saúde}

Bioética é um termo polissêmico, compreendido como ciência, disciplina ou movimento de intervenção social que se fundamenta nas consequências resultantes da ação humana, com o objetivo de melhorar as realidades da vida e do viver, por meio de reflexões sobre a forma como o ser humano se relaciona entre si e com o meio ambiente (18). Sua origem pauta-se em dois documentos, com um enfoque inicial na biologia e medicina: o primeiro escrito sobre o assunto foi feito por Fritz Jahr, em 1927, onde apresentava a bioética como a emergência de obrigações éticas não apenas com o homem, mas com todos os seres vivos; o segundo é o livro publicado em 1971, pelo oncologista Van Ressenlaer Potter, que a apresentou como ciência da sobrevivência, a partir de sua preocupação com os avanços tecnológicos e com os efeitos que o meio ambiente exercia na saúde humana devido ao comportamento do homem (18).

Atualmente a bioética se expandiu para dar respostas mais adequadas aos problemas da realidade, com uma perspectiva mais humanista e comunitária relacionada ao desenvolvimento humano. Além das questões sobre conflitos éticos decorrentes do avanço da ciência e tecnologia, de novos tratamentos e saúde pública em geral, incorporou também questões sobre desigualdade e injustiça social, tais como: direitos humanos e cidadania, alocação de recursos humanos e materiais escassos, preservação da biodiversidade, finitude dos recursos naturais, equilíbrio do ecossistema, alimentos transgênicos, racismo e outras formas de discriminação (19).

Das reflexões da bioética sobre esses variados conflitos, surgem valores humanos que precisam ser resguardados e terem os direitos referentes garantidos, mediante instrumentos jurídicos que delineiam e delimitam as ações humanas no contexto dos direitos humanos. Destarte, entra-se no campo das normas do biodireito.

De maneira simples, Barboza (20) conceitua biodireito como "ramo do Direito que trata da teoria, da legislação e da jurisprudência relativas às normas reguladoras da conduta 
humana em face dos avanços da Biologia, da Biotecnologia e da Medicina”. Entretanto, alerta para a sua complexidade, pois que a maioria dos casos de adequação dos comportamentos científicos à axiologia extracientífica se produz de forma espontânea, por auto-restrições e controles autônomos. Mas em outros casos, os modelos que vão ser adotados devem ser adequados fora do campo científico, através do Direito, estabelecendo os valores que a sociedade, em um momento histórico determinado, considera relevantes. Isso justifica a explicação de que "O conhecimento jurídico e a tecnologia evoluem em modo e velocidade distintos, cada qual respeitando suas características" (21).

É oportuno elucidar que a rápida ampliação do conhecimento e da capacidade de interferência sobre a vida obrigam a sociedade a refletir de uma nova maneira sobre a vida, sobre as pesquisas científicas e sobre a responsabilidade com relação ao que se pode e ao que se deve fazer com o ser vivo (22). Isso porque as interferências podem ter efeitos admiráveis ou ocasionar danos sociais, políticos, econômicos e jurídicos.

É dado como certo que a IA em saúde ampliará as chances de cura, a qualidade e a esperança de vida, uma vez que "está revolucionando a maneira como os serviços de saúde trabalham para melhorar a qualidade dos cuidados e oferecer melhores resultados a custos mais baixos" (2). Entretanto, surgem importantes questionamentos em diferentes dimensões éticas, sociais e econômicas, que implicam novos dilemas bioéticos e de biodireitos.

São implicações que envolvem desafios para certificar e regulamentar softwares como dispositivo médico; as relações trabalhistas, devido à ideia de que a IA substituirá profissionais de saúde; a relação médico-paciente, ao sofrer interferência de planos de saúde para substituir a decisão médica; a refutação de diagnósticos de doenças graves devido à imprecisão de algoritmos; cenários susceptíveis a erros e vieses, porque é possível ensinar um viés antiético (sexista ou racista, por exemplo) para uma máquina, ou apresentar ao software uma realidade defasada e prejudicar muitos pacientes em fase de tratamento; desigualdades que dificultem o viés inclusivo de acesso universal e acesso equitativo aos novos tratamentos; a invasão de privacidade; as dificuldades para estabelecer usos e usuários apropriados; as dificuldades para estabelecer a responsabilidade jurídica; e o viés inclusivo em relação a como os países de baixa e média renda se beneficiarão dos desenvolvimentos da inteligência artificial (13) (2) (14).

Tais implicações resultam em novos dilemas bioéticos sobre a dignidade da pessoa humana, portanto no âmbito dos direitos humanos. Esses dilemas não estão restritos aos 
aspectos biomédicos em si, também envolvem a humanização do atendimento e a não replicação de discriminações, desigualdades e exclusões sociais.

$\mathrm{Na}$ esteira da construção dialética complementar, as implicações do uso da IA em saúde dizem respeito ao valor por parte da bioética, e deste surge a norma como Biodireito. Uma vez que a bioética aborda questões axiológicas multidisciplinares e interdisciplinares, a perspectiva de tutela no biodireito perpassa pelo enfoque também multi e interdisciplinar dos direitos humanos.

Para colocar em prática o princípio da dignidade humana é necessária a existência de instrumentos normativos globais e locais, tanto porque os direitos humanos invocam 0 princípio da cooperação internacional, quanto porque essas questões são de natureza transnacional devido aos processos de dados e informações gerados ou usados por essas tecnologias irem além das fronteiras nacionais. Nesse sentido, organizações internacionais esforçam-se para gerar documentos que orientem as nações para a adoção de medidas em comum e que sejam ajustadas às necessidades e características regionais e locais em suas políticas e legislações. É caso da Declaração Universal sobre Bioética e Direitos Humanos.

\section{A Declaração Universal sobre Bioética e Direitos Humanos}

A Declaração Universal sobre Bioética e Direitos Humanos (DUBDH) foi proclamada pela Organização das Nações Unidas para Educação, Ciência e Cultura (UNESCO), em 2005. A adoção pelos os Estados-membros celebra o compromisso, próprio e com a comunidade internacional, de respeitar e aplicar os princípios fundamentais da bioética contidos em seu texto.

Desde as reuniões preparatórias do texto final da $\mathrm{DUBDH}$, havia posicionamentos e defesas claras sobre as questões bioéticas entre os países ricos e pobres que compõem a UNESCO, uma vez que as nações desenvolvidas defendiam a restrição da bioética aos tópicos biomédico e biotecnológico. Contudo, o Brasil defendeu a ampliação do texto para os campos sanitário, social e ambiental, com o apoio das delegações latino-americanas, dos países africanos e da Índia. O teor final da DUBDH é uma grande vitória das nações em desenvolvimento, porque democratiza a agenda da bioética do século XXI, tornando-a mais aplicada e comprometida com as populações vulneráveis (23).

A DUBDH é uma norma do soft law, não vinculante, preparada dentro de uma organização ou de um órgão subsidiário e que estabelece princípios gerais ou metas de 
longo prazo. Tem caráter solene e é adotada nas reuniões ministeriais dos conselhos ou das comissões. $\mathrm{O}$ documento harmoniza-se com todo o corpo de instrumentos jurídicos sociais e econômicos adotados pela ONU, que têm como fulcro a Declaração Universal dos Direitos Humanos. Também recepciona os instrumentos internacionais e regionais anteriormente proclamados no domínio da bioética (4).

Dentre os seus objetivos, o que mais explicita as preocupações sobre inclusão social e o uso da IA em saúde está no art.2º, f:

promover um acesso equitativo aos progressos da medicina, da ciência e da tecnologia, bem como a mais ampla circulação possível e uma partilha rápida dos conhecimentos relativos a tais progressos e o acesso partilhado aos benefícios deles decorrentes, prestando uma atenção particular às necessidades dos países em desenvolvimento (4).

A declaração revela-se importante porque consagra a bioética entre os direitos humanos internacionais e garante o respeito pela vida dos seres humanos e liberdades fundamentais, de modo que todos possam ser beneficiados pelos avanços científicos e tecnológicos.

\section{Resultados e discussão}

Da análise dos documentos, observa-se que a terminologia dos princípios do direito à saúde é formada, em sua maioria, por unitermos e os princípios da DUBDH são formados por tópicos frasais sucintos. Ambos possuem conteúdo mais principialista para o campo da bioética e do biodireito, e agrupam-se sob aspectos de fundamentalidades democráticas e derivações destas, como direitos sociais e econômicos. Os termos que identificam os princípios da RIACOCDE são mais genéricos, formados por tópicos frasais de conteúdo mais aberto e político, podendo confundi-los com diretrizes (Quadro 1). 
Quadro 1. Sistematização das terminologias dos princípios

\begin{tabular}{|c|c|c|}
\hline Direito à saúde & $\begin{array}{l}\text { Declaração Universal de } \\
\text { Bioética e Direitos Humanos } \\
\text { (DUBDH) }\end{array}$ & $\begin{array}{l}\text { Recomendação sobre IA do } \\
\text { Conselho da OCDE } \\
\text { (RIACOCDE) }\end{array}$ \\
\hline $\begin{array}{l}\text { - Dignidade da pessoa } \\
\text { humana } \\
\text { - Liberdade } \\
\text { - Igualdade } \\
\text { - Equidade } \\
\text { - Consentimento ou } \\
\text { autonomia } \\
\text { - Segurança sanitária } \\
\text { - Informação } \\
\text { - Participação da } \\
\text { comunidade } \\
\text { - Prevenção } \\
\text { - Risco } \\
\text { - Benefício } \\
\text { - Subsidiariedade } \\
\text { - Legalidade } \\
\text { - Supremacia do interesse } \\
\text { público } \\
\text { - Impessoalidade } \\
\text { - Publicidade } \\
\text { - Eficiência } \\
\text { - Moralidade }\end{array}$ & $\begin{array}{l}\text { - Dignidade humana e direitos } \\
\text { humanos } \\
\text { - Efeitos benéficos e efeitos } \\
\text { nocivos } \\
\text { - Autonomia e responsabilidade } \\
\text { individual } \\
\text { - Consentimento } \\
\text { - Proteção especial a pessoas } \\
\text { incapazes de exprimir o seu } \\
\text { consentimento } \\
\text { - Respeito pela vulnerabilidade } \\
\text { humana e integridade pessoal } \\
\text { - Respeito à Vida privada e } \\
\text { confidencialidade } \\
\text { - Igualdade, justiça e equidade } \\
\text { - Não discriminação e não } \\
\text { estigmatização } \\
\text { - Respeito pela diversidade } \\
\text { cultural e do pluralismo } \\
\text { - Solidariedade e cooperação } \\
\text { - Responsabilidade social e } \\
\text { saúde } \\
\text { - Partilha dos benefícios } \\
\text { - Proteção das gerações futuras } \\
\text { - Proteção do meio ambiente, da } \\
\text { biosfera e da biodiversidade }\end{array}$ & $\begin{array}{l}\text { - Crescimento inclusivo, } \\
\text { desenvolvimento sustentável e } \\
\text { bem-estar } \\
\text { - Valores e justiça centrados no } \\
\text { homem } \\
\text { - Transparência e explicabilidade. } \\
\text { - Robustez, segurança e proteção } \\
\text { - Prestação de contas }\end{array}$ \\
\hline
\end{tabular}

Fonte: elaborado pela autora.

Verifica-se que os princípios do direito à saúde foram utilizados na elaboração da DUBDH. A Declaração traz como inovação o detalhamento de alguns princípios fundantes sob a forma de novos princípios, dentre os quais estão: a não discriminação e não estigmatização, da justiça, do respeito à diversidade cultural e pluralismo, da solidariedade 
e cooperação, da proteção das gerações futuras e proteção do meio ambiente. São princípios detalhados decorrentes dos princípios da dignidade da pessoa humana, da igualdade e do risco.

Todos os princípios demonstram-se multidimensionais, ou seja, podem ser interpretados dentro e entre categorias porque interpenetram-se, estando profundamente associados. Não são estanques, pois que todos eles se imbricam, complementam-se e estão transversalizados pelos princípios maiores da igualdade, liberdade, justiça e paz, em afinação com o fulcro dos direitos humanos - a dignidade - e, ainda, aos princípios da universalidade e da equidade.

Ademais, refletem as necessidades bioéticas relacionadas à privacidade, proteção, segurança, autonomia e autodeterminação, a serem sanadas mediante normas do biodireito, dentro de uma ordem jurídica constitucional de diversidade e pluralismo, que tem compromisso com uma ética planetária. Consideram tanto a autonomia do indivíduo quanto das coletividades e dos territórios, as liberdades individuais e comunitárias, porque estão condicionados aos contextos social, econômico, cultural e político.

Dessa maneira, convergem para temas (Quadro 2) que permitem identificar os princípios em categorias mais tradicionais - biológicas, biotecnológicas e biomédicas -; categorias amplas e inclusivas - sanitária, social, cultural, econômica, laboral, ambiental, moral e ética -; e categorias organizativas-jurídicas - responsabilidade individual, social, coletiva e política (sanitária, penal, civil e profissional).

Quadro 2. Categorização dos princípios em temas

\begin{tabular}{|l|l|l|l|}
\hline Direito à saúde & $\begin{array}{l}\text { Declaração Universal } \\
\text { de Bioética }\end{array}$ & $\begin{array}{l}\text { Recomendação sobre } \\
\text { IA do Conselho da } \\
\text { OCDE }\end{array}$ & $\begin{array}{l}\text { Temas de inserção } \\
\text { dos princípios }\end{array}$ \\
\hline $\begin{array}{l}\text { - Dignidade da } \\
\text { pessoa humana } \\
\text { - Liberdade } \\
\text { - Igualdade } \\
\text { - Equidade } \\
\text { - Subsidiariedade }\end{array}$ & $\begin{array}{l}\text { - Dignidade humana e } \\
\text { direitos humanos } \\
\text { - Igualdade, justiça e } \\
\text { equidade } \\
\text { - Não discriminação e não } \\
\text { estigmatização }\end{array}$ & $\begin{array}{l}\text {-Valores e justiça } \\
\text { centrados no homem } \\
\text { - Crescimento inclusivo, } \\
\text { desenvolvimento } \\
\text { sustentável e bem-estar }\end{array}$ & • Democracia \\
\hline $\begin{array}{l}\text { - Segurança } \\
\text { sanitária } \\
\text { - Benefício }\end{array}$ & $\begin{array}{l}\text { - Efeitos benéficos e } \\
\text { efeitos nocivos }\end{array}$ & & $\begin{array}{l}\text { - Sanitário, } \\
\text { econômico, social, } \\
\text { cultural e ambiental }\end{array}$ \\
\hline
\end{tabular}




\begin{tabular}{|c|c|c|c|}
\hline $\begin{array}{l}\text { - Prevenção } \\
\text { - Participação da } \\
\text { comunidade }\end{array}$ & $\begin{array}{l}\text { - Respeito pela } \\
\text { diversidade cultural e do } \\
\text { pluralismo } \\
\text { - Solidariedade e } \\
\text { cooperação } \\
\text { - Partilha dos benefícios } \\
\text { - Proteção do meio } \\
\text { ambiente, da biosfera e } \\
\text { da biodiversidade } \\
\text { - Proteção das gerações } \\
\text { futuras }\end{array}$ & & \\
\hline $\begin{array}{l}\text { - Consentimento ou } \\
\text { autonomia } \\
\text { - Informação }\end{array}$ & $\begin{array}{l}\text { - Autonomia e } \\
\text { responsabilidade } \\
\text { individual } \\
\text { - Consentimento } \\
\text { - Proteção especial a } \\
\text { pessoas incapazes de } \\
\text { exprimir o seu } \\
\text { consentimento } \\
\text { - Respeito pela } \\
\text { vulnerabilidade humana e } \\
\text { integridade pessoal } \\
\text { - Respeito à Vida privada } \\
\text { e confidencialidade }\end{array}$ & $\begin{array}{l}\text { - Transparência e } \\
\text { explicabilidade }\end{array}$ & - Privacidade \\
\hline \multirow{2}{*}{$\begin{array}{l}\text { - Risco } \\
\text { - Supremacia do } \\
\text { interesse público } \\
\text { - Legalidade }\end{array}$} & \multirow[t]{2}{*}{$\begin{array}{l}\text { - Responsabilidade social } \\
\text { e saúde }\end{array}$} & $\begin{array}{l}\text { - Robustez, segurança e } \\
\text { proteção }\end{array}$ & \multirow[t]{2}{*}{ - Política } \\
\hline & & - Prestação de contas & \\
\hline
\end{tabular}

Fonte: elaborado pela autora.

O agrupamento dos princípios apresenta uma disposição que mostra a convergência para as questões bioéticas, representadas por perspectivas axiológicas, econômicas, sociais, legais, institucionais, organizacionais e ambientais (Quadro 2).

No Quadro 3, comparando os princípios da RIACOCDE às diretrizes do mesmo documento, nota-se que ambos contêm o referencial ético da DUBDH e do direito à saúde. Utilizam de valores democráticos e dos direitos humanos, que norteiam ações sob uma perspectiva crítica, de política proativa, socialmente e politicamente compromissadas com o desenvolvimento sustentável, no âmbito de uma agenda global. 
Quadro 3. Aspectos comparativos entre os princípios e diretrizes da Recomendação sobre IA do Conselho da OCDE

\begin{tabular}{|c|c|}
\hline Princípios & Diretrizes para políticas nacionais \\
\hline $\begin{array}{l}\text { 1. Crescimento inclusivo, desenvolvimento sustentável } \\
\text { e bem-estar: } \\
\text { - resultados benéficos para as pessoas e o planeta; } \\
\text { - promover a inclusão de minorias; reduzir as } \\
\text { desigualdades; } \\
\text { - proteger os ambientes naturais. }\end{array}$ & $\begin{array}{l}\text { 1. Investir em pesquisa e desenvolvimento: } \\
\text { - investimento público a longo prazo e incentivar o } \\
\text { investimento privado em questões técnicas } \\
\text { desafiadoras e em implicações sociais, legais, } \\
\text { éticas e políticas; } \\
\text { • investimento público e incentivar o investimento } \\
\text { privado em conjuntos de dados abertos que } \\
\text { respeitam a privacidade e a proteção. }\end{array}$ \\
\hline $\begin{array}{l}\text { 2. Valores e justiça centrados no homem: } \\
\text { - respeitar o estado de direito, direitos humanos e } \\
\text { valores democráticos (liberdade, dignidade e } \\
\text { autonomia, privacidade e proteção dados, não } \\
\text { discriminação e igualdade, diversidade, justiça social e } \\
\text { direitos trabalhistas). }\end{array}$ & $\begin{array}{l}\text { 2. Promover um ecossistema digital: } \\
\text { - desenvolvimento e o acesso a um ecossistema } \\
\text { digital confiável; } \\
\text { - apoiar o compartilhamento seguro, justo, legal e } \\
\text { ético de dados. }\end{array}$ \\
\hline $\begin{array}{l}\text { 3. Transparência e explicabilidade: } \\
\text { • transparência e divulgação responsável sobre } \\
\text { sistemas; informações significativas e consistentes. }\end{array}$ & $\begin{array}{l}\text { 3. Moldar um ambiente de política favorável: } \\
\text { - que suporte uma transição ágil do estágio de } \\
\text { pesquisa e desenvolvimento para o de implantação } \\
\text { e operação de sistemas confiáveis; } \\
\text { - revisar e adaptar estruturas de políticas, } \\
\text { regulamentos e mecanismos de avaliação. }\end{array}$ \\
\hline $\begin{array}{l}\text { 4. Robustez, segurança e proteção dos sistemas: } \\
\text { - não representem riscos de segurança irracionais; } \\
\text { - garantir a rastreabilidade dos conjuntos de dados; } \\
\text { - gerenciamento de riscos, segurança digital, } \\
\text { segurança e preconceito. }\end{array}$ & $\begin{array}{l}\text { 4. Fortalecer a capacidade humana e preparar a } \\
\text { transformação do mercado de trabalho: } \\
\text { - capacitar as pessoas a usar e interagir } \\
\text { efetivamente com os sistemas; } \\
\text { - garantir uma transição justa para os } \\
\text { trabalhadores; } \\
\text { - promover o uso responsável da IA no trabalho, } \\
\text { qualidade dos empregos e promover o } \\
\text { empreendedorismo. }\end{array}$ \\
\hline $\begin{array}{l}\text { 5. Prestação de contas: } \\
\text { • responsabilidade pelo bom funcionamento dos } \\
\text { sistemas; } \\
\text { • respeito aos princípios descritos na recomendação. }\end{array}$ & $\begin{array}{l}\text { 5. Cooperação internacional: } \\
\text { • promover esses princípios; } \\
\text { - promover o compartilhamento do conhecimento; } \\
\text { • promover o desenvolvimento de padrões } \\
\text { técnicos globais; } \\
\text { - medir a pesquisa, o desenvolvimento e a } \\
\text { implantação da IA, e } \\
\text { - reunir evidências para avaliar o progresso na } \\
\text { implementação desses princípios. }\end{array}$ \\
\hline
\end{tabular}

Fonte: elaborado pela autora com dados da pesquisa documental. 
Pode-se dizer que os princípios contemplam a noção abrangente do direito à saúde de proporcionar o bem estar, e o referencial de promoção desse bem estar é por meio do desenvolvimento sustentável da IA, com responsabilidade e respeito ao valor do trabalho humano, aos demais seres vivos e ao planeta. Para tal, é importante a cooperação internacional entre os países, inclusive os países em desenvolvimento, para que a implementação da IA aconteça sob o imperativo democrático da participação de governos e agentes interessados (Quadro 3).

\section{Aspectos intersetoriais dos princípios da RIACOCDE}

A RIACOCDE não se detém em aspectos técnicos relacionados apenas à pesquisa, engloba também produtos e usos. Aponta que os princípios devem nortear a implementação de IA em muitos setores, incluindo a saúde, de forma responsável e cooperativa entre os agentes e interessados, concentrando-se em questões técnicas, sociais, éticas e legais. Apresenta a necessidade de interação, uma vez que os princípios se originam de múltiplos e complexos aspectos interdisciplinares, a desencadear a articulação intersetorial dos governos e agentes interessados. Além disso, a RIACOCDE considera que, na construção das políticas de implementação da IA, devem estar presentes as considerações sobre populações vulneráveis e os riscos que afetam as pessoas (individual e coletivamente).

O conjunto dos princípios e diretrizes da RIACOCDE demonstra uma flexibilidade para modelar os interesses com equilíbrio e harmonia, para que a relação entre a IA e a sociedade seja confiável, segura, justa, legal e ética.

O direito à saúde e seus princípios são o arcabouço que deve orientar todas as políticas sociais e as legislações em seu campo. Consoante a Magna Carta que tutela o direito à saúde como direito fundamental (art. 6º); sob a fundamentação máxima da dignidade da pessoa humana no Estado Democrático de Direito (art. 1ํ, III); como direito individual, coletivo e em desenvolvimento (art. 196) a ser prestado obrigatoriamente pelo Estado de modo universal, igualitário e equitativo, e pela subsidiariedade é livre à iniciativa privada (art. 199)(5).

Os princípios são valores compartilhados pela sociedade, espelhando a sua ideologia e seus postulados básicos. Abrigados explicita ou implicitamente na Constituição, a síntese desses valores no ordenamento jurídico serve de guia para a interpretação, baseada na identificação do princípio maior que rege o tema a ser analisado, considerando-se desde os 
princípios mais genéricos até os mais específicos, culminando na formulação da norma concreta que regerá a espécie (24).

Além de ser imperativo constitucional, esse arcabouço é evidenciado também em normas internacionais, como a DUBDH e a RIACOCDE, sendo que a última não é específica para a implementação de IA no setor da saúde, mas, guardadas as devidas proporções, seus princípios e diretrizes podem ser interpretados para a saúde no que diz respeito às implicações éticas e valorativas das atividades, produtos e serviços inerentes à IA.

Nessa ótica, os princípios apresentados nos documentos analisados trazem os referenciais éticos e valorativos preconizados pela Constituição Federal para a saúde, e convergem dos princípios genéricos da igualdade, liberdade, universalidade, equidade, justiça e paz, para o fulcro maior da dignidade da pessoa humana. É assim porque a complexidade das questões tratadas no biodireito requer a obediência à base principiológica da Constituição Federal, pois que o sistema normativo como um todo não possui condições de estabelecer uma legislação que regulamente ponto a ponto todas as inovações e criações biotecnológicas da atualidade (25).

Surgem novos contextos que ampliam a dimensão das responsabilidades, dos direitos e dos desafios biopolíticos, o que exige adequação do marco legal e uma mobilização das pessoas e da sociedade civil organizada no sentido de preservar a autonomia, a liberdade e minimizar os efeitos nocivos das novas tecnologias. Tal exigência conduz a refletir sobre a importância da qualidade de vida e do bem-estar social, a repensar os produtos tecnológicos a partir de uma lógica original, na qual o bem-estar e a felicidade das pessoas possam ser percebidos a partir de termos distintos da simples expansão do lucro e do poder (26).

As grandes questões éticas colocadas em função do avanço científico e tecnológico não se referem às potencialidades do ser humano, mas a suas responsabilidades, pois na prática nem todos os caminhos trazem benefícios para a humanidade, há consequências custosas em longo prazo. O problema não está em rejeitar a utilização de novas tecnologias por não serem moralmente aceitas pela sociedade, e sim no controle ético que deve ser exercido. Implica reconhecimento e a valorização da vulnerabilidade, que requer rigor ético na avaliação e gerenciamento dos riscos que podem incidir sobre indivíduos ou grupos de indivíduos, e também ao meio ambiente natural (27). A ideia de vulnerabilidade tratada na RIACOCDE envolve a vulnerabilidade social e programática, pela preocupação demonstrada 
com o bem-estar das pessoas e do planeta por meio da promoção do crescimento inclusivo e de uma sociedade justa, pautada em valores éticos e democráticos.

A RIACOCDE refere-se à responsabilidade social, individual, social, coletiva e política, atreladas diretamente ao reconhecimento dos riscos, e das indigitadas vulnerabilidades. Entretanto, a responsabilidade referente aos novos riscos, consequência dos novos desafios e inovações, não está claramente definida. A abordagem é genérica, silente em muitos aspectos, em especial das possíveis tipologias inerentes à IA quanto ao poder de autodecisão, autoevolução e autoaprendizagem de alguns sistemas, embora a Recomendação reconheça que as futuras aplicações de IA e suas implicações são difíceis de prever. O documento coloca a responsabilização pelo bom funcionamento dos sistemas de IA sobre os atores de IA, que são aqueles que desempenham um papel ativo no ciclo de vida desses sistemas, incluindo organizações e indivíduos que implantam ou operam a IA. Não atribui a responsabilidade ao sistema artificial.

A perspectiva, então, é que o desenvolvimento sustentável da IA em saúde, com responsabilidade e respeito ao valor do trabalho humano, respeito aos demais seres vivos e ao planeta, necessita da cooperação internacional entre os países pobres e ricos. É necessária a intervenção e participação democrática dos governos e das representações sociais e organizacionais interessadas.

Assim, é oportuna a explanação de que a saúde, enquanto um bem jurídico em construção, também deve ter os olhos da justiça postos sobre si. É preciso antecipar-se aos avanços e progressos tecnológicos ligados à qualidade de vida e ao bem-estar, discutindo a garantia do acesso a novas tecnologias antes mesmo de serem efetivadas; é preciso buscar a horizontalização dos benefícios da evolução tecnológica e do saber cientifico e a possibilidade de compartilharmos, por todos os povos, dos benefícios oriundos dos conhecimentos científicos essenciais à plena e à mais ampla concepção da realização da saúde (28).

O Brasil aderiu à RIACOCDE e já lançou esforços para se adequar aos seus princípios e diretrizes. Tramita na Câmara Legislativa Federal o Projeto de Lei nำ 21/2020 para a criação do marco legal do desenvolvimento da inteligência artificial no Brasil. Outro passo importante foi dado pelo Ministério da Ciência, Tecnologia, Inovações e Comunicações (MCTIC), por meio de consulta pública com o objetivo colher subsídios para a construção de 
uma Estratégia Brasileira de Inteligência Artificial (EBIA) que permita potencializar os benefícios da IA para o país, mitigando eventuais impactos negativos sobre o país (29)(30).

A elaboração da EBIA visa definir objetivos concretos e pontos prioritários da IA que serão estabelecidos segundo fundamentos e diretrizes em consonância com a comunidade internacional. A proposta apresentada pelo MCTIC sugere uma organização em seis eixos temáticos verticais - qualificações por um futuro digital; força de trabalho; pesquisa, desenvolvimento, inovação e empreendedorismo; aplicação pelo governo; aplicação nos setores produtivos; e segurança pública - e três eixos transversais: legislação, regulação e uso ético; aspectos internacionais; e governança de IA. A área da saúde possui pontos para discussão nos eixos de pesquisa e de aplicação nos setores produtivos, com destaque para contribuições que apontem maneiras possíveis de promover maior integração entre instituições científicas, empresas de tecnologia e órgãos governamentais na realização de pesquisa, desenvolvimento e inovação em IA no Brasil; e o papel do governo, em termos de políticas públicas e de conformação do ambiente regulatório, para impulsionar o uso de IA nos setores da economia (30).

Para o eixo legislação, regulação e uso ético, o mais detalhado na EBIA, a preocupação é estabelecer um ponto de equilíbrio entre proteção e salvaguarda de direitos à proteção de dados pessoais e à prevenção de discriminação e viés; fornecer estruturas adequadas de incentivo ao desenvolvimento de tecnologia cujas potencialidades ainda não foram plenamente compreendidas; e estabelecer parâmetros legais de segurança jurídica quanto à responsabilidade dos diferentes atores que participam da cadeia de valor de sistemas autônomos. Nesse, eixo há várias discussões com nexo na área da saúde, como as maneiras de incorporar princípios éticos na pesquisa e na utilização de IA; a necessidade de estabelecer salvaguardas para o uso de IA na saúde e quais seriam essas salvaguardas; quais princípios éticos devem ser observados no Brasil; circunstâncias e contextos para preservar a determinação humana em decisões tomadas por sistemas de IA nas aplicações na medicina; necessidade urgente de atualização das normas vigentes; papel desempenhado por códigos de conduta, regras de boas práticas corporativas e padrões voluntários; importância de robôs gerarem impostos para suporte às necessidades dos humanos de aplicações em saúde; e, responsabilidade civil, penal e administrativa por danos causados com uso da IA (30). 
A proposta cita exemplos internacionais de normas jurídicas que regulam diferentes aspectos concretos de IA, baseadas em princípios gerais e parâmetros éticos a serem adotados por atores públicos e privados. Dentre esses instrumentos estão os Princípios da OCDE sobre Inteligência Artificial, de 2019; a Declaração de Toronto: Protegendo os Direitos à Igualdade e à Não-Discriminação em Sistemas de Aprendizado por Máquinas, de 2018; as Diretrizes Universais para Inteligência Artificial (Public Voice Coalition, 2018); e a Declaração sobre Ética e Proteção de Dados em Inteligência Artificial, de 2018 (30).

É necessário, portanto, prosseguir na reflexão e aprimoramento desses temas, tendo sempre como norte o princípio da dignidade da pessoa humana e suas repercussões no campo da saúde.

\section{Considerações finais}

Em tempos de pandemia global ocasionada pelo Covid-19, os receios e questões éticas suscitadas pelo uso das novas tecnologias da medicina do futuro dão lugar ao medo da morte, ao pânico pelas consequências sociais e econômicas, e a necessidade de soluções emergenciais e urgentes. São fatores que levam à liberação de tecnologias da telemedicina e recursos baseados em inteligência artificial ainda em testes, sem os critérios e protocolos necessários. É importante reforçar os mecanismos de segurança dos direitos à informação em saúde; à autonomia do paciente; ao livre esclarecimento e consentimento; aos dados pessoais e privacidade; aos cuidados e conduta ética etc. Não se pode esperar que a pandemia passe, que sejam recuperadas as condições normais para a vida e existência humana, para que as questões bioéticas voltem à tona.

É importante que haja o desenvolvimento e a aplicação de instrumentos normativos cogentes, que representem a vontade social e legislativa sobre a implementação da IA em saúde em cada país, como resultado dos referenciais principiológicos apresentados pelo arcabouço da saúde como direito, da Declaração Universal de Bioética e Direitos Humanos (DUBDH) e da Recomendação sobre IA do Conselho da OCDE (RIACOCDE).

Este estudo apresentou uma reflexão sobre o uso da IA em saúde com base nos princípios dos direitos humanos que fundamentam os princípios do direito à saúde, da bioética e da recomendação internacional da OCDE. O objetivo foi encontrar possíveis convergências entre os princípios, bem como ampliações destes nos documentos citados. Os princípios convergem para os aspectos valorativos, econômicos, legais, políticos, sociais, 
biológicos, biomédicos, biotecnológicos e organizacionais presentes nas preocupações bioéticas em relação à IA em saúde. São eles que devem embasar e equilibrar as políticas sociais (públicas e privadas) em interligação ativa com o sistema de proteção jurídico-social, dentro da estreita e necessária relação entre bioética e biodireito de uma sociedade democrática.

Com base nas reflexões apresentadas e nas convergências entre os princípios do direito à saúde, da DUBDH e da RIACOCDE, pode-se considerar a possibilidade de um desenho de políticas de IA em saúde que contemple critérios mínimos como:

- colaboração dos governos, desenvolvedores e agentes interessados, para promover o desenvolvimento e o acesso às tecnologias de IA com o máximo de efeitos benéficos, e critérios de inclusão e redução de desigualdades sociais;

- regulamentações e garantias que tutelem de forma ética a transparência, o controle, a privacidade, a proteção do trabalho, a segurança, as gerações futuras e o meio ambiente para minimizar os erros e mitigar os riscos;

- critérios de responsabilização jurídica distribuída entre os desenvolvedores e operadores das tecnologias de IA; e

- respeito aos direitos e liberdades das minorias, das diversidades e pluralismos, e proteção dos ambientes naturais para estimular a ambiência e a transição digital da IA de forma sustentável.

A convergência entre os princípios do direito à saúde, da DUBDH e da RIACOCDE centra-se na dignidade da pessoa humana, como guia para que as decisões a serem tomadas sobre os sistemas de IA em saúde e sua implementação sejam feitas de forma segura, imparcial e justa para toda a sociedade.

O Brasil deve considerar os seus reais contextos de país latino americano em desenvolvimento, permeado por diversidades socioculturais e biodiversidade, mas também por severas desigualdades sociais e econômicas. É possuidor de um sistema de saúde que, embora carente de melhor gestão e recursos, tem dado respostas possíveis e necessita ser defendido e fortalecido. Portanto, são muitos fatores com características próprias que devem ser considerados para a adoção de políticas sociais e legislações sobre a implantação e implementação da IA em saúde, de modo que não produza e/ou reproduza iniquidades em saúde por basear-se em parâmetros equivocados. 


\section{Referências}

1. Organização das Nações Unidas ONU. Declaração Universal dos Direitos Humanos. 10 dezembro de 1948 [Acesso em 24.mar.2020]. Disponível em: http://www.direitoshumanos.usp.br/index.php/Declara\%C3\%A7\%C3\%A3o-Universal-dosDireitos-Humanos/declaracao-universal-dos-direitos-humanos.html.

2. Organização Pan-Americana da Saúde. OMS, OPAS e UIT discutem uso de inteligência artificial na saúde durante workshop no Brasil. 24.jan.2020 [Acesso em 24.jan.2020]. Disponível em:

https://www.paho.org/bra/index.php?option=com_content\&view=article\&id=6097:oms-opase-uit-discutem-uso-de-inteligencia-artificial-na-saude-durante-workshop-nobrasil\&Itemid=812.

3. Organisation for Economic Co-operation and Development OECD. Recommendation of the Council on Artificial Intelligence. 2019 [Acesso em 24.jan.2020]. Disponível em: https://legalinstruments.oecd.org/en/instruments/OECD-LEGAL-0449.

4. Organização das Nações Unidas para Educação, Ciência e Cultura. Declaração Universal sobre Bioética e Direitos Humanos. Comissão Nacional da UNESCO - Portugal. 2006 [Acesso em 17.mar.2020]. Disponível em:

https://unesdoc.unesco.org/ark:/48223/pf0000146180_por.

5. Brasil. Constituição da República Federativa do Brasil [Internet]. Brasília: Edições Câmara; 2016 [Acesso em 15.mar.2020]. Disponível em: http://www.camara.leg.br/editora.

6. Clement JM. Les Grands Principes du Droit de la Sant. France. Editeur: Lés Études Hospitaliers; 2005.

7. Aith FMA. Teoria Geral do Direito Sanitário Brasileiro. [Tese]. São Paulo: Programa de Pós-Graduação em Saúde Pública, Universidade de São Paulo; 2006 [Acesso em 29.jan.2020]. Disponível em: http://livros01.livrosgratis.com.br/cp019543.pdf.

8. Elias A N Direito Sanitário: autonomia e princípios. Revista de Direito Sanitário. 2008 jul./out., 9(2). p.47-64.

9. Pardo A. Léxico de Bioética. Madrid: Espasa Calpe; 1999 [Acesso em 29.jan.2020]. Disponível em: https:/www.unav.edu/web/unidad-de-humanidades-y-etica-medica/materialde-bioetica/lexico-de-bioetica.

10. Organização das Nações Unidas para Educação, Ciência e Cultura. Diccionario latinoamericano de bioética (dir. Juan Carlos Tealdi). Bogotá: UNESCO - Red Latinoamericana y del Caribe de Bioética: Universidad Nacional de Colombia; 2008 [Acesso em 30.jan.2020]. Disponível em:

https://unesdoc.unesco.org/ark:/48223/pf0000161848.

11. Ministério da Saúde. Biblioteca Virtual em Saúde. Descritores em Ciências da Saúde (DeCS). Disponível em: http://decs.bvs.br/. 
12. Gorender EF. Novas Tecnologias em Medicina e Qualidade de Vida. In: Gutierrez GL, Carvalho THPF, Gonçalves A (organizadores). Qualidade de vida e novas tecnologias. Campinas: Ipes editorial; 2007. p. 97-104.

13. Mesko B. The guide to the futuristic medicine. EUA: Webicina Kft, 2014. Edição Kindle.

14. Hackmed Conference. 31 jan a 02 fev 2020, São Paulo: Hospital das Clínicas, 2020.

15. Brasil. O Brasil e a OCDE. 2020 [Acesso em 20.fev. 2020]. Disponível em: http://www.itamaraty.gov.br/pt-BR/politica-externa/diplomacia-economica-comercial-efinanceira/15584-o-brasil-e-a-ocde.

16. Mazzuoli VO. Curso de direito internacional público. 5.ed. São Paulo: Editora Revista dos Tribunais; 2011.

17. Organisation for Economic Co-operation and Development OECD. Legal Instruments. 2020 [Acesso em 24.jan.2020]. Disponível em:

https://legalinstruments.oecd.org/fr/instruments?mode=advanced\&typelds=2\&committeelds $=1837 \&$ themelds=12\&yearFrom=2019\&yearTo=2020\&dateType=adoption .

18. Azevedo MAS. Origens da Bioética. Porto (Portugal): Nascer e Crescer [Internet]. 2010 dez [Acesso em 24.jan.2020]; 19(4): 255-259. Disponível em:

http://www.scielo.mec.pt/scielo.php?script=sci_arttext\&pid=S0872-

07542010000400005\&lng=pt.

19. Garrafa V, Porto D. Intervention bioethics: a proposal for peripheral countries in a context of power and injustice. Bioethics. 2003 [Acesso em 24.mar.2020]; 17(5-6). p. 399416. Disponível em:

https://www.researchgate.net/profile/Volnei_Garrafa/publication/8779156_Intervention_Bioe thics_A_Proposal_For_Peripheral_Countries_in_A_Context_of_Power_and_Injustice/links/ 5bbb79544585159 e8d8c3fd6/Intervention-Bioethics-A-Proposal-For-Peripheral-Countriesin-A-Context-of-Power-and-Injustice.pdf.

20. Barboza HH. Princípios da Bioética e do Biodireito. Revista Bioética. 2000 [Acesso em 24.jan.2020]; 8(2). Disponível em:

http://revistabioetica.cfm.org.br/index.php/revista_bioetica/article/view/276/275.

21. Mabtum MM, Marchetto PB. O debate bioético e jurídico sobre as diretivas antecipadas de vontade. São Paulo: Editora UNESP; 2015. Edição Kindle.

22. Bueno E. Reflexões Sobre as Inovações Médicas e a Produção de Saúde e Qualidade de Vida. In: Gutierrez GL, Carvalho THPF, Gonçalves A, (organizadores). Qualidade de vida e novas tecnologias. Campinas: Ipes editorial; 2007. p. 77-86.

23. Garrafa V. Apresentação da Declaração Universal sobre Bioética e Direitos Humanos. [s.n.t.] [Acesso em 17.mar.2020]. Disponível em:

http://bvsms.saude.gov.br/bvs/publicacoes/declaracao_univ_bioetica_dir_hum.pdf. 
24. Barroso LR. O novo direito constitucional brasileiro. Belo Horizonte: Fórum; 2013.

25. Gewehr MF. O princípio da dignidade da pessoa humana e as questões de biodireito na visão dos tribunais brasileiros. Revista Direito e Justiça - Reflexões Sociojurídicas. 2010 nov [Acesso em 19.mar.2020]; Ano X (15). Disponível em:

http://srvapp2s.santoangelo.uri.br/seer/index.php/direito_e_justica/article/view/688/348.

26. Gutierrez GL, Vilarta R. Desenvolvimento e Apropriação Social das Novas Tecnologias para a Qualidade de Vida. In: Gutierrez GL, Carvalho THPF, Gonçalves A, (organizadores). Qualidade de vida e novas tecnologias. Campinas: Ipes editorial; 2007. p.17-22.

27. Cruz MR, Oliveira SLT, Portillo JAC. A Declaração Universal sobre Bioética e Direitos Humanos - contribuições ao Estado brasileiro. Revista Bioética. 2010 [Acesso em 17.mar.2020]; 18(1). p. 93-107. Disponível em:

http://revistabioetica.cfm.org.br/index.php/revista_bioetica/article/view/538/524.

28. Rodrigueiro DA, Moreira JCD. O direito social à saúde na perspectiva da constituição de 1988: um direito individual, coletivo e em construção. Revista do Instituto de Pesquisas e Estudos. 2016 jul./dez; 50(66). p.143-159.

29. Brasil. Projeto de lei $\mathrm{n}^{\circ}$ de 2020, 4 de fevereiro de 2020. Estabelece princípios, direitos e deveres para o uso de inteligência artificial no Brasil. Brasília, 4 fev. 2020 [Acesso em 19.mar.2020]. Disponível em:

https://www.camara.leg.br/proposicoesWeb/fichadetramitacao?idProposicao=2236340.

30. Ministério da Ciência, Tecnologia, Inovações e Comunicações. Consulta Pública sobre Estratégia Brasileira de Inteligência Artificial. 12.dez.2019 [Acesso em 27.jan.2020]. Disponível em:

http://www.mctic.gov.br/mctic/opencms/inovacao//paginas/politicasDigitais/Inteligencia/Artifi cial.html.

Como citar este artigo:

Sousa MEA. Direitos humanos e princípios comuns entre inteligência artificial e direito à saúde. Cadernos lberoAmericanos de Direito Sanitário. 2020 jul./set.; 9(3): 26-48.

http://dx.doi.org/10.17566/ciads.v9i3.658 